\title{
16 Pharmaceutical Compounds in Estuarine and Coastal Waters
}

\author{
John L. Zhou and Zulin Zhang
}

\section{CONTENTS}

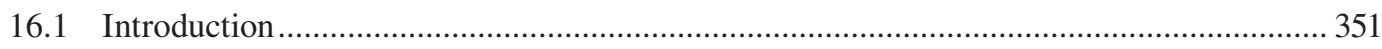

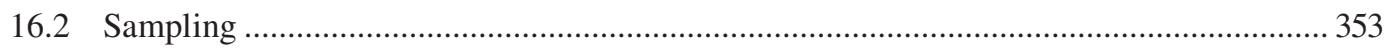

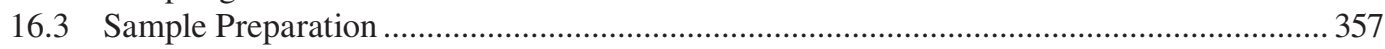

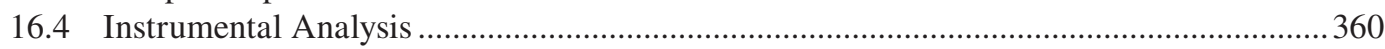

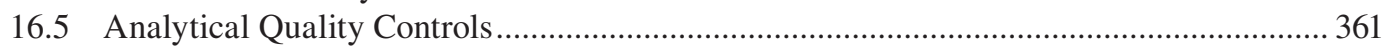

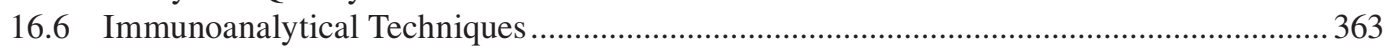

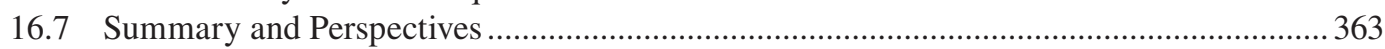

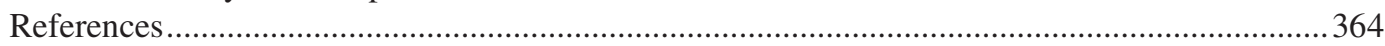

\subsection{INTRODUCTION}

Pharmaceuticals and personal care products (PPCPs) are a group of emerging contaminants of environmental concern that have remained largely unrecognized as such until recent advances in trace-level analytical measurements (Cha et al., 2006; Erickson, 2002; Gros et al., 2006; Lindsey et al., 2001). There is growing concern over the occurrence and fate of PPCPs in the environment, with evidence of adverse effects in terrestrial and aquatic organisms, and also the potential of some antibiotics to induce resistance in naturally occurring bacterial strains (Hirsch et al., 1998).

Over three thousand chemical substances are used in human and veterinary medicine (Ternes et al., 2004). Such pharmaceuticals include antiphlogistics/anti-inflammatory drugs, contraceptives, $\beta$-blockers, lipid regulators, tranquilizers, antiepileptics, and antibiotics (Ternes et al., 2004; Petrovic et al., 2005). Some typical pharmaceuticals classified by groups according to therapeutical effect and physicochemical properties are listed in Table 16.1. During and after treatment, humans and animals excrete a combination of intact and metabolized pharmaceuticals, many of which are generally soluble in water and have been discharged to the aquatic environment with little evaluation of possible risks or consequences to humans and the environment. In addition, chemicals that are components of personal care products number in the thousands, and are contained in skin care products, dental care products, soaps, sunscreen agents, and hair care products. Annual production exceeds $1 \times 10^{6}$ tonnes worldwide (e.g., $>553,000$ tonnes was produced in Germany alone in 1993; Daughton and Ternes, 1999). Included in this category are fragrances (e.g., nitro and polycyclic musks), UV blockers (e.g., methylbenzylidene camphor), and preservatives (e.g., parabens). Unlike pharmaceuticals, personal care products enter wastewater and the aquatic environment after regular use during showering or bathing. The environmental fates and effects of many cosmetic ingredients are poorly known, although considerable persistence and bioaccumulation in aquatic organisms have been reported (Daughton and Ternes, 1999; Kallenborn et al., 2001).

In many aquatic environments, particularly in North America and Europe, pharmaceuticals, hormones, metabolites, biocides, musks, and flame retardants have been measured (Ternes, 1998; 
TABLE 16.1

Pharmaceuticals and Their Physicochemical Properties

\begin{tabular}{|c|c|c|c|c|c|}
\hline Compound & Therapeutic Class & $\log \mathrm{K}_{\mathrm{ow}}$ & $\mathrm{pK}_{\mathrm{a}}$ & MW & Formula \\
\hline Ketoprofen & Analgesic/anti-inflammatories & 3.12 & 4.45 & 254 & $\mathrm{C}_{16} \mathrm{H}_{14} \mathrm{O}_{3}$ \\
\hline Naproxen & & 3.18 & 4.15 & 230 & $\mathrm{C}_{14} \mathrm{H}_{14} \mathrm{O}_{3}$ \\
\hline Ibuprofen & & 3.97 & 4.91 & 206 & $\mathrm{C}_{13} \mathrm{H}_{18} \mathrm{O}_{2}$ \\
\hline Indomethacine & & 4.27 & 4.5 & 358 & $\mathrm{C}_{19} \mathrm{H}_{16} \mathrm{ClNO}_{2}$ \\
\hline Diclofenac & & 4.51 & 4.14 & 296 & $\mathrm{C}_{14} \mathrm{H}_{10} \mathrm{Cl}_{2} \mathrm{NO}_{2}$ \\
\hline Meclofenamic acid & & 5.12 & 4.2 & 241 & $\mathrm{C}_{15} \mathrm{H}_{15} \mathrm{NO}_{2}$ \\
\hline Acetaminophen & & 0.46 & 9.38 & 151 & $\mathrm{C}_{8} \mathrm{H}_{9} \mathrm{NO}_{2}$ \\
\hline Propyphenazone & Lipid regulators/cholesterol- & 1.94 & $\mathrm{n} / \mathrm{a}$ & 230 & $\mathrm{C}_{14} \mathrm{H}_{18} \mathrm{~N}_{2} \mathrm{O}$ \\
\hline Clofibric acid & lowering statin drugs & $\mathrm{n} / \mathrm{a}$ & $\mathrm{n} / \mathrm{a}$ & 214 & $\mathrm{C}_{10} \mathrm{H}_{11} \mathrm{O}_{3} \mathrm{Cl}$ \\
\hline Gemfibrozil & & 4.77 & $\mathrm{n} / \mathrm{a}$ & 250 & $\mathrm{C}_{15} \mathrm{H}_{22} \mathrm{O}_{3}$ \\
\hline Bezafibrate & & 4.25 & $\mathrm{n} / \mathrm{a}$ & 362 & $\mathrm{C}_{19} \mathrm{H}_{20} \mathrm{ClNO}_{4}$ \\
\hline Pravastatin & & 3.1 & $\mathrm{n} / \mathrm{a}$ & 446 & $\mathrm{C}_{23} \mathrm{H}_{36} \mathrm{O}_{7}$ \\
\hline Mevastatin & & 3.95 & $\mathrm{n} / \mathrm{a}$ & 391 & $\mathrm{C}_{25} \mathrm{H}_{38} \mathrm{O}_{5}$ \\
\hline Carbamazepine & Psychiatric drugs & 2.47 & 7 & 236 & $\mathrm{C}_{15} \mathrm{H}_{12} \mathrm{NO}$ \\
\hline Fluoxetine & & 3.82 & 8.7 & 309 & $\mathrm{C}_{17} \mathrm{H}_{18} \mathrm{~F} 3 \mathrm{NO}$ \\
\hline Paroxetine & & 3.95 & $\mathrm{n} / \mathrm{a}$ & 329 & $\mathrm{C}_{19} \mathrm{H}_{20} \mathrm{FNO}_{3}$ \\
\hline Lansoprazole & Antiulcer agent & 2.58 & 8.73 & 369 & $\mathrm{C}_{16} \mathrm{H}_{14} \mathrm{~F}_{3} \mathrm{~N}_{3} \mathrm{O}_{2} \mathrm{~S}$ \\
\hline Loratadine & Histamine $\mathrm{H}_{1}$ and $\mathrm{H}_{2}$ receptor & 5.20 & $\mathrm{n} / \mathrm{a}$ & 383 & $\mathrm{C}_{22} \mathrm{H}_{23} \mathrm{ClN}_{2} \mathrm{O}_{2}$ \\
\hline Famotidine & antagonists & -0.64 & $\mathrm{n} / \mathrm{a}$ & 337 & $\mathrm{C}_{8} \mathrm{H}_{15} \mathrm{~N}_{7} \mathrm{O}_{2} \mathrm{~S}_{3}$ \\
\hline Ranitidine & & 0.27 & $\mathrm{n} / \mathrm{a}$ & 314 & $\mathrm{C}_{13} \mathrm{H}_{22} \mathrm{~N}_{4} \mathrm{O}_{3} \mathrm{~S}$ \\
\hline Erythromycin & Antibiotics & 3.06 & 8.8 & 734 & $\mathrm{C}_{37} \mathrm{H}_{67} \mathrm{NO}_{13}$ \\
\hline Azythromycin & & 4.02 & 8.74 & 749 & $\mathrm{C}_{38} \mathrm{H}_{72} \mathrm{~N}_{2} \mathrm{O}_{12}$ \\
\hline Sulfamethoxazole & & 0.89 & 6.0 & 253 & $\mathrm{C}_{10} \mathrm{H}_{11} \mathrm{~N}_{3} \mathrm{O}_{3} \mathrm{~S}$ \\
\hline Trimethoprim & & 0.91 & 7.12 & 290 & $\mathrm{C}_{14} \mathrm{H}_{18} \mathrm{~N}_{4} \mathrm{O}_{3}$ \\
\hline Ofloxacin & & $\mathrm{n} / \mathrm{a}$ & $\mathrm{n} / \mathrm{a}$ & 361 & $\mathrm{C}_{18} \mathrm{H}_{20} \mathrm{FN}_{3} \mathrm{O}_{4}$ \\
\hline Atenolol & $\beta$-Blockers & 0.16 & 9.6 & 266 & $\mathrm{C}_{14} \mathrm{H}_{22} \mathrm{~N}_{2} \mathrm{O}_{3}$ \\
\hline Sotalol & & 0.24 & $\mathrm{n} / \mathrm{a}$ & 272 & $\mathrm{C}_{12} \mathrm{H}_{20} \mathrm{~N}_{2} \mathrm{O}_{3} \mathrm{~S}$ \\
\hline Metoprolol & & 1.88 & 9.68 & 267 & $\mathrm{C}_{15} \mathrm{H}_{25} \mathrm{NO}_{3}$ \\
\hline Propranolol & & $1.2-3.48$ & 9.5 & 260 & $\mathrm{C}_{16} \mathrm{H}_{21} \mathrm{NO}_{2}$ \\
\hline Meberverine & Gastrointestinal & $\mathrm{n} / \mathrm{a}$ & $\mathrm{n} / \mathrm{a}$ & 429 & $\mathrm{C}_{25} \mathrm{H}_{35} \mathrm{O}_{5}$ \\
\hline Thioridazine & Antidepressant & $\mathrm{n} / \mathrm{a}$ & $\mathrm{n} / \mathrm{a}$ & 371 & $\mathrm{C}_{21} \mathrm{H}_{26} \mathrm{~N}_{2} \mathrm{~S}_{2}$ \\
\hline Tamoxifen & Anticancer & $\mathrm{n} / \mathrm{a}$ & $\mathrm{n} / \mathrm{a}$ & 372 & $\mathrm{C}_{26} \mathrm{H}_{29} \mathrm{NO}$ \\
\hline Monensin & Growth promoters & $2.75-3.89$ & 6.65 & 692 & $\mathrm{C}_{36} \mathrm{H}_{61} \mathrm{NaO}_{11}$ \\
\hline
\end{tabular}

Note: $\log \mathrm{K}_{\mathrm{ow}}, \log$ of the octanol-water partition coefficient; $\mathrm{pK}_{\mathrm{a}, 1} \log$ of the not available.

Kolpin et al., 2002; Hirsch et al., 1999; Hilton and Thomas, 2003). One of the principal sources is through the release of municipal wastewater. Some pharmaceuticals do not readily biodegrade in a marine environment, and have been detected in seawater (Weigel et al., 2002; Thomas and Hilton, 2004) and sediments (Samuelsen et al., 1992). Weigel et al. (2002) reported a wide distribution of clorfibric acid, caffeine, and N,N-diethyl-3-toluamide (DEET, an insect repellent) in concentrations up to 19,16 , and $1.1 \mathrm{ng} \mathrm{L}^{-1}$, respectively, throughout the North Sea, off Scotland, the outer and inner German Bight, as well as the Danish and Norwegian coasts. Samples collected from UK 
estuaries had clorfibric acid concentrations of approximately $100 \mathrm{ng} \mathrm{L}^{-1}$ in two samples (Thomas and Hilton, 2004). Other frequently measured pharmaceutical compounds found in UK estuaries included clotrimazole (a tepical antifungal agent, in 59\% of samples, up to $22 \mathrm{ng} \mathrm{L}^{-1}$ ), ibuprofen (an analgestic, in 50\% of samples, up to $569 \mathrm{ng} \mathrm{L}^{-1}$ ), and propranolol (an antihypertensive drug, in $41 \%$ of samples, up to $56 \mathrm{ng} \mathrm{L}^{-1}$ ), with several other drugs appearing in approximately one-third of the samples at lower concentrations (Thomas and Hilton, 2004).

The concentrations of pharmaceuticals present in the aquatic environment are generally in the sub ng L ${ }^{-1}$ range and do not necessarily represent a major threat to drinking water quality. The consequence of a continuous presence of low concentrations of pharmaceuticals for ecosystems is still not fully understood. A discussion of various aspects of ecotoxicology of pharmaceuticals in the environment can be found in recent reviews (Cunningham et al., 2006; Fent et al., 2006; Crane et al., 2006; Hernando et al., 2006). It is quite clear that environmental risk assessment must be based on reliable data about the actual concentrations of pharmaceuticals in aquatic systems. Therefore, efficient analytical methods are of major importance.

Fast progress in the development of analytical procedures for residue analysis of pharmaceutical drugs has been facilitated by the existence of considerable expertise in other microorganic pollutants residue analysis. Strategies successfully used for routine analysis of traces of some polar organic contaminants have been modified and subsequently applied to residue analysis of pharmaceuticals. In many cases, the common procedures involve sampling, sample treatment (e.g., preconcentration, cleanup step) by solid-phase extraction (SPE) or related techniques, followed by analysis using chromatography in combination with mass spectrometry (MS) as detector. When residue analysis of pharmaceuticals became an important issue in the 1990s, gas chromatography (GC) was the preferred chromatographic technique together with various derivatization procedures for the analytes. Nowadays, GC-MS may still be the perfect technique for certain classes of pharmaceuticals (Togola and Budzinski, 2008), although highperformance liquid chromatography (HPLC) hyphenated with atmospheric pressure ionization-MS has established itself as a better choice for simultaneous determination of pharmaceuticals of widely differing structures (Buchberger, 2007). In this chapter, the analysis of pharmaceuticals in estuarine and coastal waters will be discussed, including the sampling, preconcentration, and instrumental measurement.

\subsection{SAMPLING}

The first task in any analysis is sampling. The sample being taken should be representative, the composition of which is as close as possible to the whole mass of whatever (e.g., estuarine water) is being analyzed. Obtaining a good sample is a crucial first step in the chemical analysis process. Prior to sampling, a sampling strategy should be drawn concerning the locations of sampling, the number of samples to be taken, where to conduct replicate sampling, size of samples, and storage and transport of samples (see Chapter 1). Preparation should also ensure that all the in situ measurement equipment is calibrated, and necessary sampling tools and containers are cleaned appropriately before sampling.

There are two sampling methods, spot and passive sampling, which are complementary to each other. Currently, the most widely used technique for performing monitoring of organic contaminants is spot sampling followed by laboratory-based extraction and analysis. In general, spot sampling uses a glass sampler or stainless steel sampler such as buckets (Gulkowska et al., 2007), some of which can be opened underwater to prevent the sampling of the surface microlayer (Zhou et al., 1996). The sample volume is typically 1-2 L (Gulkowska et al., 2007; Roberts and Thomas, 2006), although for seawater samples this may be increased to 10-100 L. General biocides such as sodium azide (final concentration of $0.02 \mathrm{M}$ ) are added to each sample on site to inactivate bacteria and prevent sample degradation during storage and processing. The samples are stored in a refrigerator below $4^{\circ} \mathrm{C}$ until filtration and extraction. Prior to use, all glassware is thoroughly soaked with 
detergents (e.g., Decon-90) and cleaned with ultrapure water, before further treatment (e.g., rinsed with distilled solvents such as dichloromethane and methanol, or baked in a furnace). The procedure should be adjusted for the compounds to be analyzed, based on their physicochemical properties (e.g., solubility, polarity).

Spot sampling is a well-established technique that is easy to perform and inexpensive, and requires limited expertise. However, it only yields an instantaneous measurement of pollutant levels and suffers from the uncertainty of short- and long-term concentration variations, which occur in the aquatic environment. An increase in sampling frequency or the use of flowand time-weighted automatic samplers may reduce such uncertainty; however, the associated increase in costs can be prohibitive. There has been rapid development in the use of passive sampling devices such as polar organic chemical integrative sampler (POCIS) (Alvarez et al., 2004), Chemcatcher (Mills et al., 2007), and silicon rod (Paschke et al., 2007) that allow continuous monitoring of aqueous pollutants, the disadvantage of using organisms (passive sampler could mimic the bioconcentration of pollutants in aquatic organisms but not suffer from adverse effects as organisms). Of the various passive sampling devices, the most widely used is POCIS, which comprises a solid receiving phase (sorbent) sandwiched between two microporous polyethersulfone (PES) membranes (Figure 16.1a; Zhang et al., 2008). POCIS samples from water and thereby enables the chemical concentration to be estimated as follows (Alvarez et al., 2004; Vrana et al., 2005):

$$
\mathrm{M}_{\mathrm{s}}=\mathrm{C}_{\mathrm{w}} \mathrm{R}_{\mathrm{s}} \mathrm{t}
$$

where $M_{s}$ is the mass of analytes in the receiving phase at time $t$, and $C_{w}$ represents time-weighted average concentration in water during the deployment period. $\mathrm{R}_{\mathrm{s}}$ is the sampling rate of the system, which may be interpreted as the volume of water cleared of analyte per unit of exposure time by the device (Vrana et al., 2006; Zhang et al., 2008). Although little has been reported on the application of POCIS for pharmaceutical residue measurements in seawater, it has been successfully applied in surface and estuarine water (Jones-Lepp et al., 2004; Petty et al., 2004; Togola and Budzinski, 2007). Figure $16.1 \mathrm{~b}$ and $\mathrm{c}$ shows the operating process for applying POCIS to pharmaceutical monitoring in river and estuarine waters (Zhang et al., 2008).

The POCIS is versatile, and by changing the sequestrating medium, specific chemicals or chemical classes can be targeted. It is common to have POCIS of several different configurations deployed together to maximize the data obtained. There are two configurations of POCIS that are typically used. One is a generic system that is useful for general hydrophilic organic contaminant purposes, and the other is for pharmaceutical sampling. The generic configuration contains the triphasic sorbent admixture of Isolute $\mathrm{ENV}^{+}$polystyrene divinylbenzene (Argonaut Technologies, Redwood City, California) and Ambersorb 1500 carbon (Rohm and Haas, Philadelphia, Pennsylvania) dispersed on S-X3 Biobeads (200-400 mesh, Bio-Rad, Hercules, California). This mixture exhibits excellent trapping and recovery of many pesticides, natural and synthetic hormones, and other wastewaterrelated contaminants (Alvarez et al., 2004, 2005). The pharmaceutical configuration uses the Oasis HLB sorbent (Waters, Milford, Massachusetts) for sequestering the chemicals of interest. This configuration is necessary, as many pharmaceuticals, with multiple functional groups, have a tendency to strongly bind to the carbonaceous component of the sorbent admixture. The membrane acts as a semipermeable barrier, allowing chemicals of interest to pass through to the sorbent, while excluding particulate matter, biogenic material, and other large, potentially interfering substances. The polyethersulfone membrane (Pall Gelman Sciences, Ann Arbor, Michigan) contains water-filled pores, $0.1 \mu \mathrm{m}$ in diameter, to facilitate transport of the hydrophilic chemicals. The POCIS was designed to mimic respiratory exposure of aquatic organisms to dissolved chemicals without the inherent problems of metabolism, depuration of chemicals, avoidance of contaminated areas, and mortalities of test organisms. Also, dietary uptake of polar organic compounds likely represents only a small fraction of residues accumulated in aquatic organism tissues (Huckins et al., 1997). 

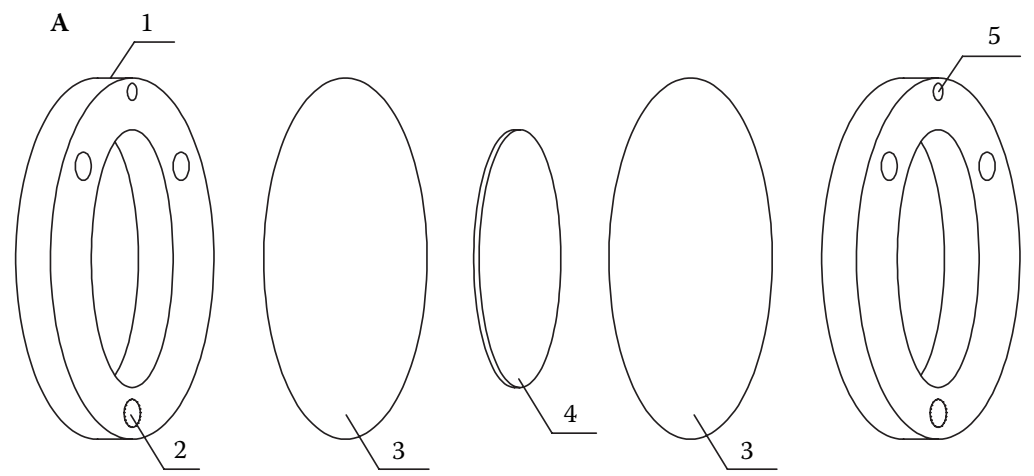

(1) PTFE holder, (2) Screw, (3) Membrane, (4) Sorbe nt, (5) Hole
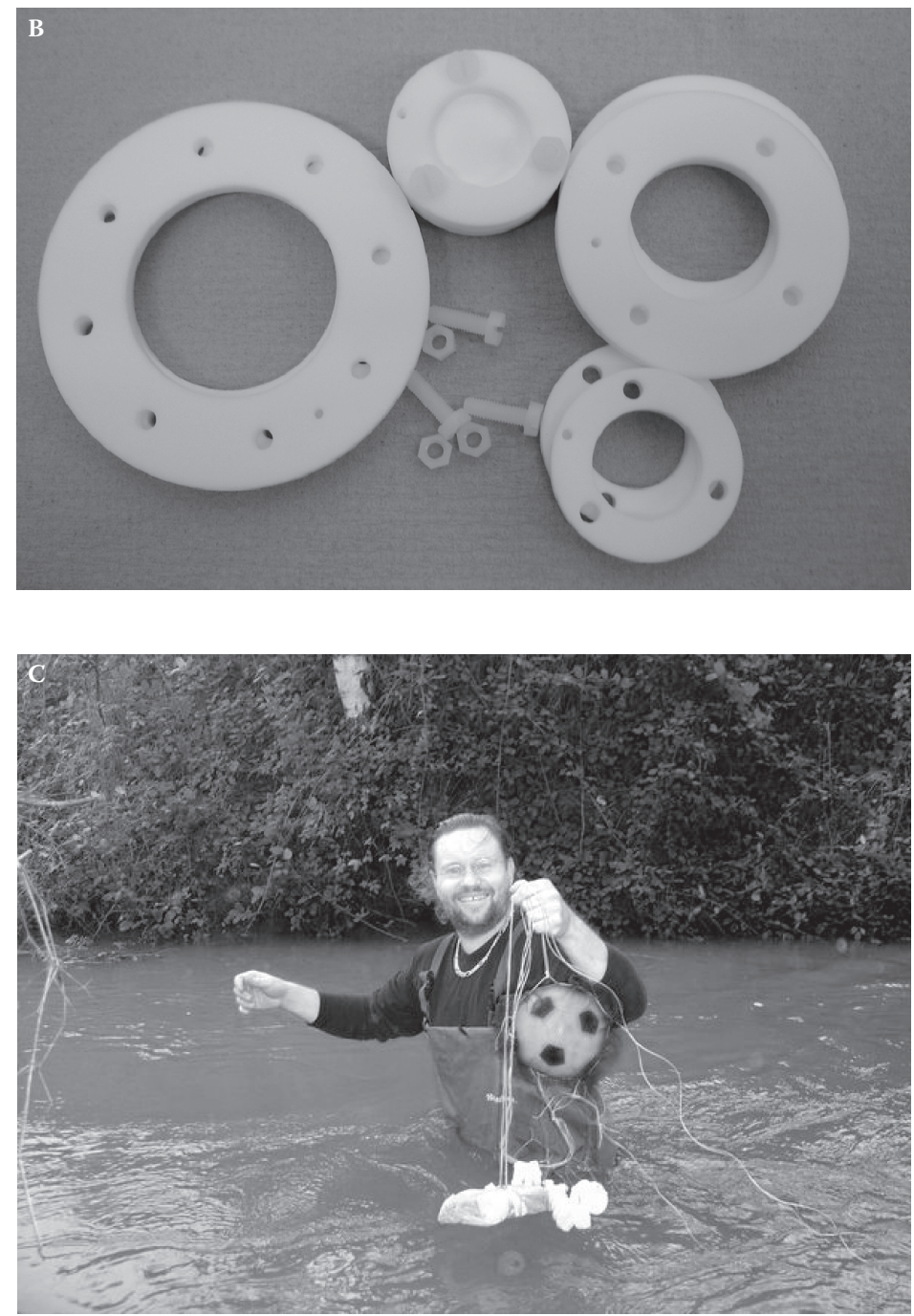

FIGURE 16.1 The POCIS device and its application to pharmaceutical analysis in river and estuarine waters. (a) Component parts of a POCIS, (b) assembled sampling device, and (c) use of sampler device in river and estuarine waters. 


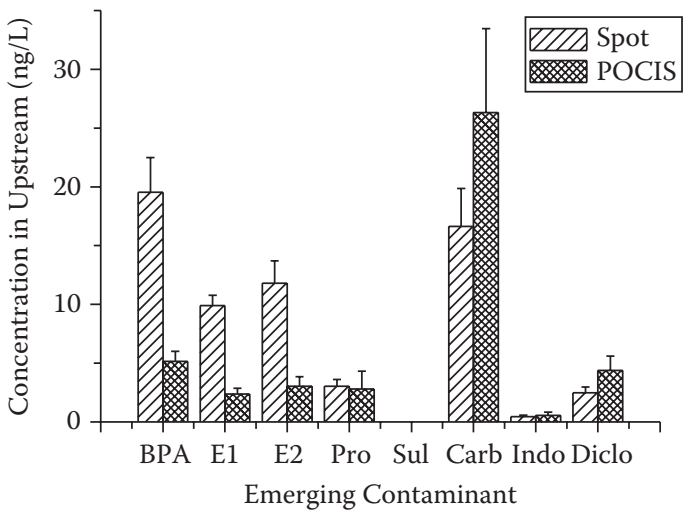

(a)

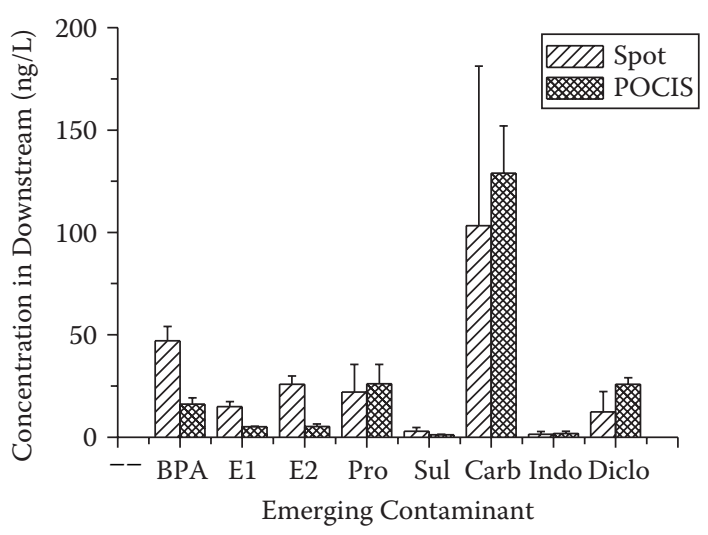

(b)

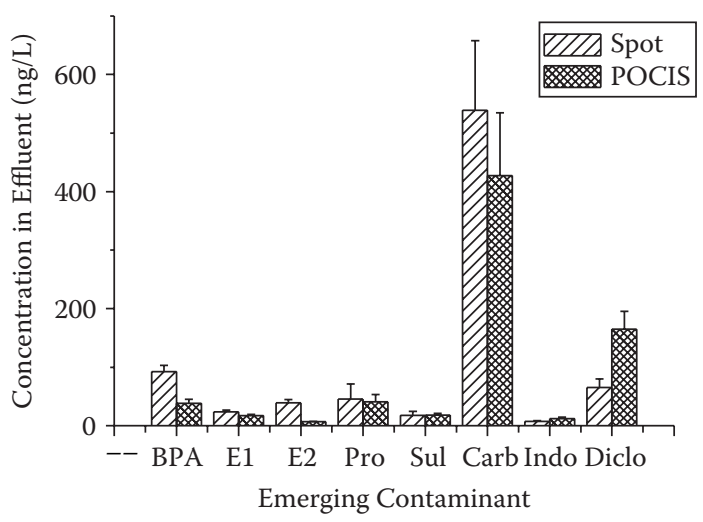

(c)

FIGURE 16.2 Comparison of the mean contaminant concentrations between spot water sampling and those predicted by POCIS in (a) upstream, (b) downstream, and (c) effluent outfall, Ouse Estuary, West Sussex, UK. BPA, bisphenol A; E1, estrone; E2, 17ß-estradiol; Pro, Propranolol, Sul, sulfamethoxazole; Carb, carbamazepine; Indo, indomethacine; Diclo: diclofenac. 
Thus, the POCIS provides a worst-case exposure scenario for aquatic organisms, enables a concentration of sufficient amounts of bioavailable hydrophilic organic chemicals for some biomarker tests, and permits determination of the biologically relevant time-weighted average concentrations in water.

The POCIS devices can be deployed at the sampling site for a duration ranging from 1 week to 2 months (Alvarez et al., 2005; Zhang et al., 2008). Quality control is achieved using both fabrication and field blanks $(n=3)$ for each analytical technique. Fabrication blanks account for any background contribution due to interferences from POCIS components and for contamination incurred during laboratory storage, processing, and analytical procedures. Field blank POCISs are used as (QC) samples for transport, deployment, and retrieval procedures (note that these POCIS blanks are sealed again in the same shipping cans and stored frozen during the exposure period). The field blank POCISs are treated identically as the deployed devices, with the exception that they are not exposed to waters at the monitoring sites.

The procedures for the recovery of sequestered chemical residues from the deployed POCIS are as follows: Briefly, the POCISs are disassembled and the sorbent transferred into glass gravity-flow chromatography columns or glass beakers (Alvarez et al., 2005; Zhang et al., 2008). Chemical residues are recovered from the sorbent by organic solvent elution/extraction. Methanol is widely used to recover the pharmaceuticals. The extracts are reduced in volume by rotary evaporation and under a gentle stream of nitrogen, and then are ready for further instrumental analysis.

Zhang et al. (2008) has described the use of POCIS for analysis of emerging contaminants, including pharmaceuticals, and compared the predicted compound concentrations in water with those measured by spot sampling. As shown in Figure 16.2, for the pharmaceuticals propranolol, sulfamethoxazole, carbamazepine, indomethacine, and diclofenac, their mean aqueous concentrations measured by spot sampling varied: 3.0-45.6 ng L ${ }^{-1}$, <LOD-17.6 ng L ${ }^{-1}, 16.6-539 \mathrm{ng} \mathrm{L}^{-1}$, 0.4-7.2 $\mathrm{ng} \mathrm{L}^{-1}$, and 2.4-65.2 $\mathrm{ng} \mathrm{L}^{-1}$, respectively. Their concentrations predicted by POCIS were 2.8-40.5 $\mathrm{ng} \mathrm{L}^{-1},<\mathrm{LOD}-18.2 \mathrm{ng} \mathrm{L}^{-1}, 26.3-427 \mathrm{ng} \mathrm{L}^{-1}, 0.5-11.9 \mathrm{ng} \mathrm{L}^{-1}$, and 4.4-165 $\mathrm{ng} \mathrm{L}^{-1}$, respectively. It is apparent that for most samples, the predicted pharmaceutical concentrations by POCIS are similar to those by spot sampling. In addition, POCIS was validated and deployed for monitoring pharmaceuticals in estuarine systems (Togola and Budzinski, 2007), confirming the potential application of passive samplers for routine monitoring of seawater quality.

\subsection{SAMPLE PREPARATION}

The sample preparation is an important step in analysis, particularly since the concentration levels of pharmaceuticals found in environmental water samples are generally too low to allow a direct injection into a chromatographic system. Therefore, efficient preconcentration steps are necessary that should also result in some sample cleanup. Several techniques have been developed and optimized, with solid-phase extraction (SPE) being the most frequent. Also, solid-phase microextraction (SPME), liquid-phase microextraction (LPME), and lyophilization have been applied (Fatta et al., 2007). In a review of thirty-two pharmaceutical studies, Fatta et al. (2007) found that most (twenty-eight studies) used SPE for extraction from water samples. This extraction procedure can be based on multiple equilibria between the liquid phase and the sorbent in SPE cartridges.

Pharmaceuticals of adequate hydrophobicity can easily be preconcentrated using any reversedphase material such as alkyl-modified silica or polymer-based materials (Buchberger, 2007). Deprotonation of acidic compounds and protonation of basic compounds should be suppressed to ensure sufficient hydrophobicity of the analytes. Therefore, acidic pharmaceuticals should be preconcentrated under acidic conditions, whereas basic analytes should be preconcentrated at an alkaline $\mathrm{pH}$ range. Alternatively, mixed-mode SPE materials can be used that exhibit both reversed-phase and cation exchange properties due to the presence of sulfonic acid groups on the hydrophobic surface of the particles. Using acidified sample solutions, acidic and neutral analytes would be extracted by hydrophobic interactions, whereas protonated basic analytes would interact 
via ion exchange mechanisms. Such an approach has been used by, among others, Stolker et al. (2004) for SPE of a set of thirteen pharmaceuticals of different classes. Mixed-mode materials with reversed-phase and anion exchange properties have been used under slightly basic conditions for antibiotics containing carboxylic acid functionality (Benito-Pena et al., 2006).

From the practical point of view, it might be desirable to extract pharmaceuticals from water samples without any pH adjustment (Buchberger, 2007). Furthermore, various (neutral) pharmaceuticals may exhibit significant hydrophilic properties, which make it difficult to enrich them on conventional alkyl-modified silica materials. SPE procedures for extraction of polar compounds from aqueous samples are still a big challenge in analytical chemistry. A recent review has summarized new SPE materials that can improve the recoveries for polar analytes (Fontanals et al., 2005). These SPE cartridge materials are mainly polymeric sorbents that improve the retention of polar compounds either by novel functional groups in the polymeric structure (resulting in a hydrophilichydrophobic balance material) or by considerably increased surface area. Some of these new materials have turned out to be well suited for multiclass analysis of pharmaceuticals in water samples. A number of different SPE stationary phases (Table 16.2) have been evaluated for the extraction of the selected pharmaceutical compounds (Hilton and Thomas, 2003; Weigel et al., 2004; Zhang and Zhou, 2007). Nowadays, one of the most widely used sorbents is a copolymer of divinylbenzene and vinylpyrrolidone, which has been commercialized under the trade name Oasis-HLB by Waters. Weigel et al. (2004) demonstrated that this sorbent can simultaneously extract acidic, neutral, and basic pharmaceuticals at neutral $\mathrm{pH}$. Multiresidue methods for different classes of pharmaceutical using Oasis-HLB at neutral $\mathrm{pH}$ have also been reported recently by Barceló and co-workers (Gomez et al., 2006; Gros et al., 2006). Trenholm et al. (2006) developed a comprehensive method for the analysis of fifty-eight potential endocrine-disrupting compounds and pharmaceuticals using a single SPE step based on Oasis-HLB. Various other studies can be found describing the successful use of Oasis-HLB for pharmaceuticals in water (Petrovic et al., 2006; Zhang and Zhou, 2007). A typical multiresidue analysis would include filtration of the seawater, conditioning of the Oasis HLB material (between 60 and $500 \mathrm{mg}$ packed into a suitable cartridge) by several milliliters of methanol and ultrapure water, application of up to $2 \mathrm{~L}$ of sample at a flow rate of approximately $10 \mathrm{ml} \mathrm{min}^{-1}$,

\section{TABLE 16.2 \\ Different Types of SPE Cartridges Being Used for Pharmaceutical Extraction}

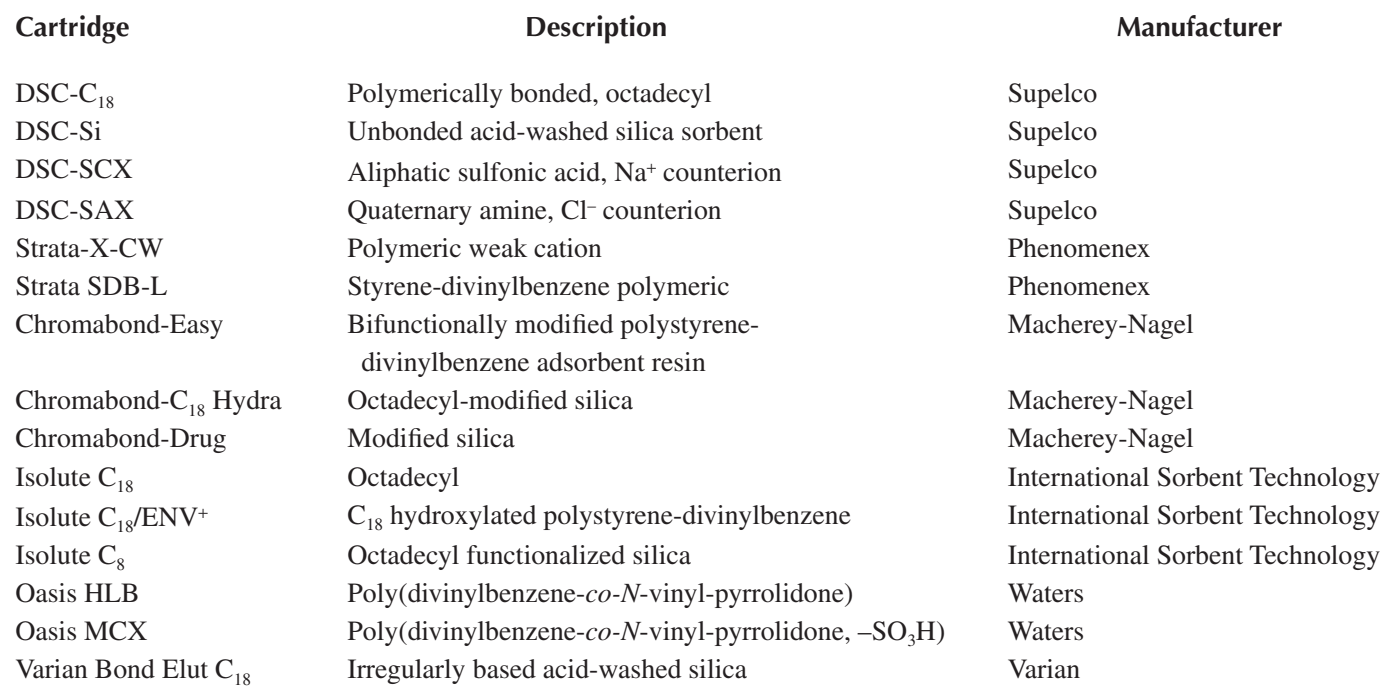




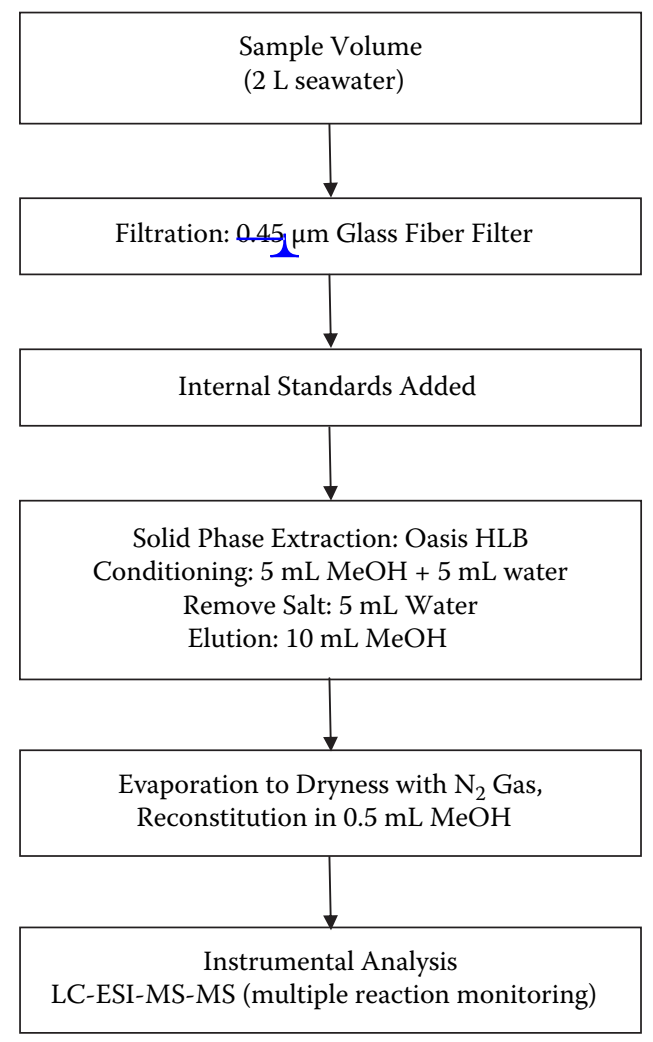

FIGURE 16.3 The procedures involved in the extraction and analysis of pharmaceuticals in estuarine and seawater samples.

rinsing the cartridge with several milliliters of ultrapure water to remove salt, drying the SPE material by applying a vacuum to remove excess water, elution with approximately $10 \mathrm{ml}$ of methanol (it may be necessary to repeat the elution step), evaporation of the extracts under a gentle stream of nitrogen (see Section 15.3.4), and reconstitution in $0.5 \mathrm{ml}$ of methanol or a mixture of methanol and ultrapure water containing internal standards that are then ready for instrumental analysis. The whole analytical procedure is illustrated in Figure 16.3 (Zhang and Zhou, 2007). All the glassware used for the extraction is baked at $400^{\circ} \mathrm{C}$ for 4 hours to eliminate any organic contaminants. All the solvents are of distilled-in-glass grade.

Hilton and Thomas (2003) have shown that Strata-X is useful for extracting selected pharmaceuticals, after comparing seven types of SPE cartridges. So in a few cases Strata-X (a polydivinylbenzene resin containing piperidone groups manufactured by Phenomenex) has been employed for generic SPE procedures (Hilton and Thomas, 2003; Roberts and Bersuder, 2006). Nebot et al. (2007) also used Strata-X successfully to determine the concentrations of a range of human pharmaceuticals in surface and wastewater, but none of the target compounds were above limit of detection (LOD) in seawater samples collected offshore Scotland. Strata-X may have properties similar to those of Oasis-HLB, but at present there is not enough data in the literature to allow this comparison to be made.

SPE of pharmaceuticals is often done offline, and is useful for on-site sampling (performing the preconcentration step in the field, followed by the elution step in the lab). It is a technique that is also well-suited for online procedures and automation in the laboratory. The SPE cartridge can be installed in the injection valve instead of the injection loop, and the preconcentrated analytes directly 
eluted onto the analytical column. An example of this approach is the work of Pozo et al. (2006), who determined sixteen antibiotics in surface and groundwater samples. In such a setup, the SPE cartridge is generally reused for a series of samples. Contrary to this configuration, fully automated SPE procedures with single-use cartridges can be realized by commercially available instrumentation, such as the SymbiosisTM Environ manufactured by Spark Ltd. This robotic system includes an automated cartridge exchange module that transfers the cartridge after the preconcentration step into the flow of mobile phase of HPLC (Rodriguez-Mozaz et al., 2007). This approach, which has primarily been used with pharmaceutical residues analysis, could be applied in seawater monitoring. There are some significant advantages with the approach (Fatta et al., 2007):

1. Direct injection of untreated seawater samples

2. Automatic sample cleanup or analyte enrichment

3. Elimination of conventional manual sample pretreatment steps

4. Faster procedures

5. Methods are less prone to errors, resulting in better reproducibility

6. Reduction of health risks

7. Samples can be run unattended (e.g., overnight or over the weekend)

\subsection{INSTRUMENTAL ANALYSIS}

The majority of pharmaceuticals lack sufficient volatility and as such are not directly compatible with GC analysis (Buchberger, 2007). Various groups of pharmaceuticals can be derivatized to make them suited for GC analysis. Although such procedures may be time-consuming and can introduce errors due to side reactions during the derivatization, they are still widely in use and well established for routine work. The major advantage of GC-MS is the fact that the usual ionization modes such as electron impact (EI) or chemical ionization (CI) are generally less affected by the matrix of the sample than ionization modes used by, for example, HPLC-MS. Typical derivatization reagents for acidic pharmaceuticals include pentafluorobenzylbromide (Reddersen and Heberer, 2003), methyl chloromethanoate (Weigel et al., 2004), methanol/BF3 (Verenitch et al., 2006), and tetrabutylammonium salts (for derivatization during injection) (Lin et al., 2005). Phenazone-type drugs have been derivatized by silylation using N-tert-butyldimethylsiyl-N-methyltrifluoroacetamide (MTBSTFA) (Zuhlke et al., 2004). Silylation procedures are also commonly used for synthetic estrogens (Quintana et al., 2004; Fernandez et al., 2007), although careful selection of the reagent and the reaction conditions is necessary to avoid side reactions (Shareef et al., 2006). Derivatization reactions that are useful for sorptive extraction combine with thermal desorption GC.

Generally, the use of GC-MS seems to be a well-established approach for residue analysis of pharmaceuticals. Correctly, there is a trend toward tandem MS techniques as the MS component of choice for this type of analysis. The advantages of such instruments will be discussed in more detail in the context of HPLC-MS.

Despite the indisputable merits of GC procedures for residue analysis of certain classes of pharmaceuticals, HPLC shows much more universal applicability (Buchberger, 2007). In some cases, when just a few analytes of a certain class are to be analyzed, even a simple UV absorbance detection may be feasible. This has been demonstrated for residues of oxytetracycline in water, which can be detected at $360 \mathrm{~nm}$ (Himmelsbach and Buchberger, 2005). Fluorescence detection may also have some benefits, as shown for the determination of some other compounds, such as anthracycline cytostatics and fluoroquinolones (Mahnik et al., 2006; Golet et al., 2001, 2002). Nevertheless, MS detection involving atmospheric pressure ionization, such as electrospray ionization (ESI), is nowadays state of the art.

Although single-quadrupole instruments have been successfully used, when HPLC-MS procedures started to be developed for pharmaceutical residue analysis (Ahrer et al., 2001), more sophisticated mass analyzers are nowadays commonly employed that allow an unequivocal confirmation 
of the identities of the analytes. Triple quadrupole (QqQ) MS instruments have become widely used with HPLC for environmental analysis. When using a QqQ instrument, false positive results can be avoided if the ions of at least two ion-ion transitions are used in combination with at least one ion intensity ratio. Several studies have dealt with HPLC-QqQ/MS for multiclass analysis of pharmaceuticals (Castiglioni et al., 2005; Rodriguez-Mozaz et al., 2004; Miao et al., 2004; Ternes et al., 2005; Gomez et al., 2006; Gros et al., 2006; Zhang and Zhou, 2007). Precursor ions and product ions used for quantification and confirmation purposes have been compiled for a wide range of pharmaceutical compounds (Petrovic et al., 2005).

An example of a typical multipharmaceutical residue analysis by HPLC-QqQ/MS is given in Figure 16.4 (Zhang and Zhou, 2007). The LC separation system is equipped with a Waters Symmetry $\mathrm{C}_{18}$ column $(4.8 \mathrm{~mm} \times 75 \mathrm{~mm}$, particle size $3.5 \mu \mathrm{m})$. The mobile phase is made of eluent $\mathrm{A}(0.1 \%$ formic acid in ultrapure water), eluent $\mathrm{B}$ (acetonitrile), and eluent $\mathrm{C}$ (methanol). The flow rate of the mobile phase is $0.2 \mathrm{ml} \mathrm{min}^{-1}$. The gradient elution is operated with $10 \%$ of eluent $\mathrm{B}$, followed by a 25 -minute gradient to $80 \%$ of eluent B and a 3-minute gradient to $100 \%$ of eluent B, and then changed to $100 \%$ of eluent $\mathrm{C}$ within 8 minutes, and hold there for 10 minutes. The system is reequilibrated for 10 minutes between runs. Typically the injection volumes are 1 to $10 \mu$ l.

A general and well-known problem of HPLC-ESI/MS is ionization suppression due to matrix components eluting at the same time as an analyte. On the one hand, ionization suppression effects can reduce the sensitivity of the method considerably; on the other hand, special care must be taken to achieve reliable quantitation. Ideally, isotopically labeled analytes should be used as internal standards but are available only in few cases for pharmaceuticals. Otherwise, standard addition methods must be applied to obtain correct quantitative data; however, such methods increase the length of the analytical procedure considerably. In all cases it makes sense to optimize the efficiency of the sample cleanup protocols in order to minimize interferences. New-generation MS instruments in some cases allow a dilution of the sample extract before injection into the HPLC system, thereby minimizing any matrix effects. Furthermore, other MS detectors such as time of flight (TOF) are more selective than QqQ, and hence more suited for samples of highly complex matrices, such as wastewater or biological extracts. However, the sensitivity of TOF currently is not as good as QqQ, and requires further development.

\subsection{ANALYTICAL QUALITY CONTROLS}

To ensure data quality, all the analytical processes should be subject to strict QC procedures to determine systematic and random errors. QC measures in relation to estuarine and coastal water analysis include the collection of blank water samples derived from laboratory-grade or organicfree water to determine if sampling procedures, sampling equipment, field conditions, sample shipment and storage (field blank), or laboratory procedures (laboratory blank) introduced target analytes into environmental samples. The spiked water samples are used to check the precision and recoveries. The blank and spiked water samples are typically made by ultrapure water taken from a Milli-Q system. Typically, several blank and spiked samples are produced with each set of real samples (ten samples for each set). In addition, the random errors involved in sampling are assessed by carrying out replicate sampling of water at the same site and the analysis of sample extracts. Internal standards (usually the target compounds labeled by stable isotopes such as ${ }^{13} \mathrm{C}$ or ${ }^{2} \mathrm{H}$ ) are used to compensate for losses involved in the sample extraction and workup, to further characterize the method performance. Prior to use, all glassware is rinsed twice with dichloromethane and methanol, or is baked at $450^{\circ} \mathrm{C}$ for 4 hours. All the solvents used are of distilled-in-glass grade. All these processes are carried out to minimize the cross-contamination and the loss of analytes through adsorption onto the surface of sampling vessels and the extraction apparatus. As seawater has a very different matrix to freshwater, more appropriate blanks should be used in the future for seawater studies. As an example, synthetic seawater prepared by dissolving appropriate amounts of key ionic substances (e.g., $\mathrm{NaCl}$ ) in ultrapure water at a concentration identical to that in real 

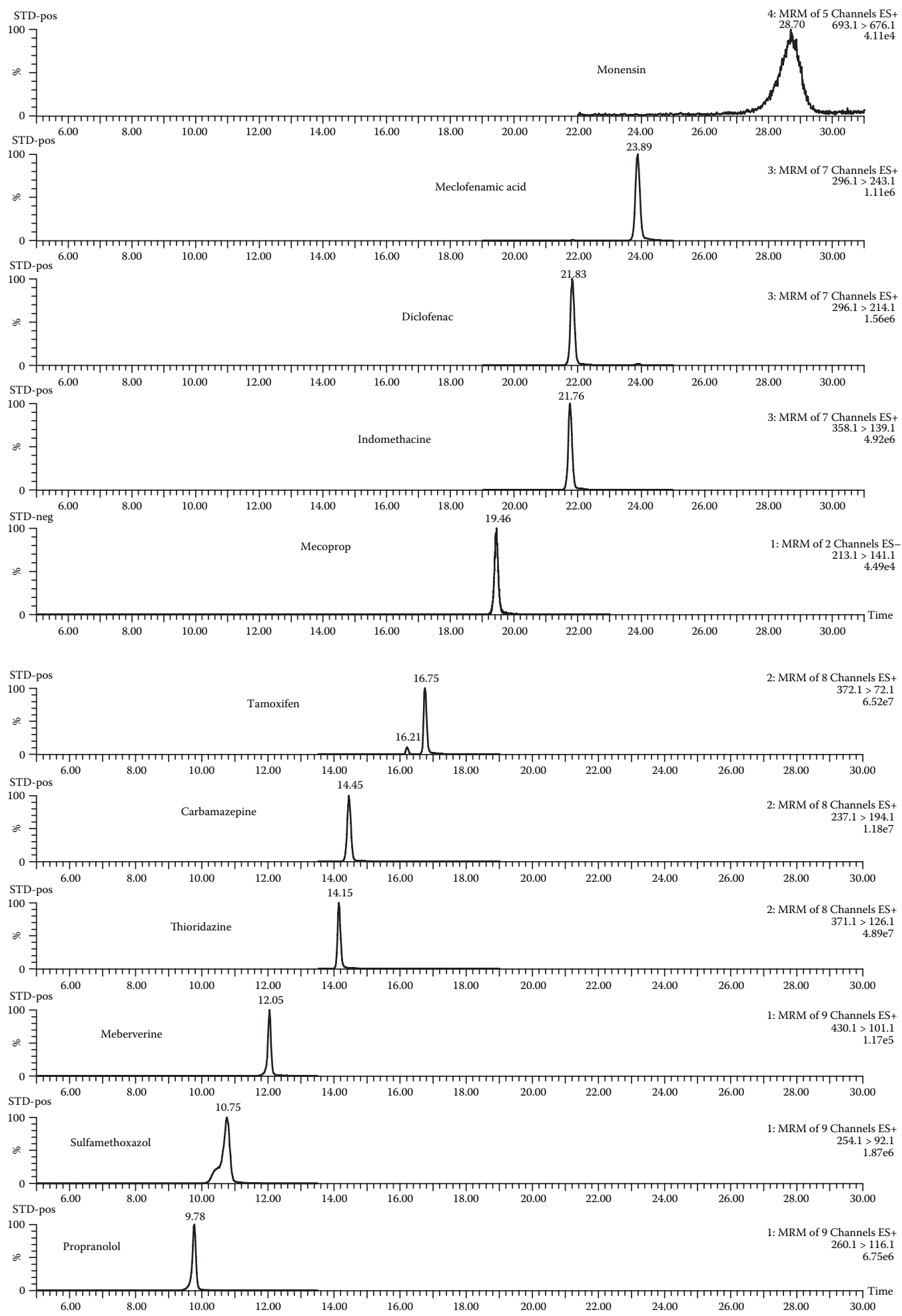

FIGURE 16.4 Chromatograms for the extracted and overlapped MRM of selected pharmaceutical compounds. 
seawater of $35 \%$ o salinity should be a more appropriate matrix for making blank samples and spiked recovery samples.

To assess systematic errors, most would use so-called recovery experiments by spiking known amounts of each target compound in seawater, followed by extraction and analysis. This gives a good indication of how reliable your measurement values are (see Chapter 1). In addition, certified reference materials (CRMs) for pharmaceuticals in seawater should be prepared in the future that can identify the closeness between a measured value (from an individual laboratory) and a certified value (from the supplier). As CRMs are vigorously tested under varying environmental conditions by the supplier and independently verified by laboratories worldwide, they become a calibration tool for the international community on pharmaceutical research. Ideally, the relative difference between measured and certified values should be as small as possible (e.g., $\pm 10 \%$ ). Such materials will ensure that everyone follows the right procedures and generates data of highest quality. In addition, this practice will ensure monitoring data obtained from any marine samples anywhere can be compared against each other, so as to identify hotspots of pharmaceutical pollution, emergence of new pharmaceuticals, and temporal variation of pharmaceutical concentrations in the estuarine and marine environment.

\subsection{IMMUNOANALYTICAL TECHNIQUES}

Immunoassays show attractive features for organic trace analysis due to the fact that they require little sample pretreatment, exhibit high sensitivity, and are inexpensive in comparison to the instrumental analysis described above. A considerable number of immunoassays have been developed and used for residue analysis of pesticides in water samples, but immunoassays for pharmaceuticals in the aquatic environment are still quite rare. Although test kits for pharmaceuticals are commercially available, these kits are in most cases optimized for samples like blood, urine, or food. The applicability to environmental samples has not been investigated in the majority of cases. Deng et al. (2003) developed a highly sensitive and specific indirect competitive enzyme-linked immunosorbent assay (ELISA) for the determination of diclofenac in water samples. When they applied the assay to analysis of diclofenac in tap and surface water as well as wastewater in Austria and Germany, they showed that ELISA-derived diclofenac concentrations in wastewater samples were about 25\% higher than those using GC-MS. The technique should be equally applicable to seawater matrices, although the sensitivity and selectivity should be further improved.

\subsection{SUMMARY AND PERSPECTIVES}

Analysis of emerging pollutants such as pharmaceutically active compounds in the aquatic environment, including seawater, was reviewed in this chapter. As pharmaceutical compounds are usually present at trace levels (e.g., $\mathrm{pg} \mathrm{L}^{-1}$ to $\mathrm{ng} \mathrm{L}^{-1}$ ) in complex matrices (e.g., seawater), it is common practice to develop extraction and analytical methods that can concentrate the target compounds while minimizing matrix interference. The analytical procedure involves many interrelated steps, including sample pretreatment (e.g., filtration), preconcentration (e.g., SPE), and analysis by advanced techniques (e.g., HPLC-MS). Residues of pharmaceuticals have most probably been present in our aquatic environment since their application, but only recently have advances in analytical chemistry and instrument performance allowed analysis of compounds at low ng $\mathrm{L}^{-1}$ concentrations. The development of advanced mass spectrometric detectors for chromatography has made a significant contribution to these achievements. The limits of detection of analytical methods may be improved even further during the next few years. Residues of pharmaceuticals in aquatic systems are not yet included in regular monitoring programs. The high costs of instrumental analysis may be prohibitive to more extended studies. A focus on a limited set of pharmaceuticals that are representative in regard to toxic effects may be advantageous (but a final selection of such a set has not yet been 
done). The importance of reliable and inexpensive biosensors may increase in the future, provided that they meet the criteria of analytical QC in the same way as traditional techniques do.

In addition, general QC procedures must be followed, including appropriate replicate sampling, sample preservation at $4^{\circ} \mathrm{C}$, application of isotopically labeled internal standards, suitable blanks, satisfactory recovery of the target compounds, and eventually use of eertified reference materials (either in-house or commercial ones). Although pharmaceutical residues in the environment are a major concern and have been widely studied in freshwater systems, the study of their occurrence, behavior, and impacts in coastal waters has been quite limited. In addition, the residues of pharmaceuticals in aquatic systems are not yet included in the regular monitoring programs of regulatory bodies. Further research on emerging pollutants such as pharmaceuticals should be extended to coastal and marine ecosystems, including polar regions, where our understanding of pharmaceutical occurrence and behavior is very limited. The low cost and robustness of passive sampling such as POCIS is recommended for routine monitoring of pharmaceuticals and other similar pollutants by governmental agencies.

\section{REFERENCES}

Ahrer, W., E. Scherwenk, and W. Buchberger. 2001. Determination of drug residues in water by the combination of liquid chromatography or capillary electrophoresis with electrospray mass spectrometry. Journal of Chromatography 910A:69-78.

Alvarez, D. A., J. D. Petty, J. N. Huckins, and T. L. Jones-Lepp. 2004. Development of a passive, in situ, integrative sampler for hydrophilic organic contaminants in aquatic environments. Environmental Toxicology and Chemistry 23:1640-48.

Alvarez, D. A., P. E. Stackelberg, J. D. Petty, J. N. Huckins, E. T. Furlong, S. D. Zaugg, and M. T. Meyer. 2005. Comparison of a novel passive sampler to standard water-column sampling for organic contaminants associated with wastewater effluents entering a New Jersey stream. Chemosphere 61:610-22.

Benito-Pena, E., A. I. Partal-Rodera, M. E. Leon-Gonzalez, and M. C. Moreno-Bondi. 2006. Evaluation of mixed mode solid phase extraction cartridges for the preconcentration of beta-lactam antibiotics in wastewater using liquid chromatography with UV-DAD detection. Analytica Chimica Acta 556:415-22.

Buchberger, W. W. 2007. Novel analytical procedures for screening of drug residues in water, waste water, sediment and sludge. Analytica Chimica Acta 593:129-39.

Castiglioni, S., R. Bagnati, D. Calamari, R. Fanelli, and E. Zuccato. 2005. A multiresidue analytical method using solid-phase extraction and high-pressure liquid chromatography tandem mass spectrometry to measure pharmaceuticals of different therapeutic classes in urban wastewaters. Journal of Chromatography 1092A:206-15.

Cha, J. M., S. Yang, and K. H. Carlson. 2006. Trace determination of $\beta$-lactam antibiotics in surface water and urban wastewater using liquid chromatography combined with electrospray tandem mass spectrometry. Journal of Chromatography $1115 \mathrm{~A}: 46-57$.

Crane, M., C. Watts, and T. Boucard. 2006. Chronic aquatic environmental risks from exposure to human pharmaceuticals. Science of the Total Environment 367:23-41.

Cunningham, V. L., M. Buzby, T. Hutchinson, F. Mastrocco, N. Parke, and N. Roden. 2006. Effects of human pharmaceuticals on aquatic life: Next steps. Environmental Science and Technology 40:3456-62.

Daughton, G. C., and T. Ternes. 1999. Pharmaceuticals and personal care products in the environment: Agents of subtle changes? Environmental Science and Technology 107:907-38.

Deng, A. P., M. Himmelsbach, Q. Z. Zhu, S. Frey, M. Sengl, W. Buchberger, R. Niessner, and D. Knopp. 2003. Residue analysis of the pharmaceutical diclofenac in different water types using ELISA and GC-MS. Environmental Science and Technology 37:3422-29.

Erickson, B. E. 2002. Analyzing the ignored environmental contaminants. Environmental Science and Technology 36:140A-45A.

Fatta, D., A. Nikolaou, A. Achilleos, and S. Meric. 2007. Analytical methods for tracing pharmaceutical residues in water and wastewater. TrAC Trends in Analytical Chemistry 26:515-33.

Fent, K., A. A. Weston, and D. Caminada. 2006. Ecotoxicology of human pharmaceuticals. Aquatic Toxicology 76:122-59. 
Fernandez, M. P., M. G. Ikonomou, and I. Buchanan. 2007. An assessment of estrogenic organic contaminants in Canadian wastewaters. Science of the Total Environment 373:250-69.

Fontanals, N., R. M. Marce, and F. Borrull. 2005. New hydrophilic materials for solid-phase extraction. TrAC Trends in Analytical Chemistry 24:394-406.

Golet, E. M., A. C. Alder, A. Hartmann, T. A. Ternes, and W. Giger. 2001. Trace determination of fluoroquinolone antibacterial agents in solid-phase extraction urban wastewater by and liquid chromatography with fluorescence detection. Analytical Chemistry 73:3632-38.

Golet, E. M., A. Strehler, A. C. Alder, and W. Giger. 2002. Determination of fluoroquinolone antibacterial agents in sewage sludge and sludge-treated soil using accelerated solvent extraction followed by solidphase extraction. Analytical Chemistry 74:5455-62.

Gomez, M. J., M. Petrovic, A. R. Fernandez-Alba, and D. Barcelo. 2006. Determination of pharmaceuticals of various therapeutic classes by solid-phase extraction and liquid chromatography-tandem mass spectrometry analysis in hospital effluent wastewaters. Journal of Chromatography 1114 A:224-33.

Gros, M., M. Petrovic, and D. Barcelo. 2006. Development of a multi-residue analytical methodology based on liquid chromatography-tandem mass spectrometry (LC-MS/MS) for screening and trace level determination of pharmaceuticals in surface and wastewaters. Talanta 70:678-90.

Gulkowska, A., Y. H. He, M. K. So, L. W. Y. Yeung, H. W. Leung, J. P. Giesy, P. K. S. Lam, M. Martin, and B. J. Richardson. 2007. The occurrence of selected antibiotics in Hong Kong coastal waters. Marine Pollution Bulletin 54:1287-306.

Hernando, M. D., M. Mezcua, A. R. Fernandez-Alba, and D. Barcelo. 2006. Environmental risk assessment of pharmaceutical residues in wastewater effluents, surface waters and sediments. Talanta 69:334-42.

Hilton, M. J., and K. V. Thomas. 2003. Determination of selected human pharmaceutical compounds in effluent and surface water samples by high-performance liquid chromatography-electrospray tandem mass spectrometry. Journal of Chromatography 1015 A:129-41.

Himmelsbach, M., and W. Buchberger. 2005. Residue analysis of oxytetracycline in water and sediment samples by high-performance liquid chromatography and immunochemical techniques. Microchimica Acta 151:67-72.

Hirsch, R., T. A. Ternes, K. Haberer, and K. L. Kratz. 1999. Occurrence of antibiotics in the aquatic environment. Science of the Total Environment 225:109-18.

Hirsch, R., T. A. Ternes, K. Haberer, A. Mehlich, F. Ballwanz, and K. Kartz. 1998. Determination of antibiotics in different water compartments via liquid chromatography-electrospray tandem mass spectrometry. Journal of Chromatography 815A:213-23.

Huckins, J. N., J. D. Petty, and J. Thomas. 1997. Bioaccumulation: How chemicals move from the water into fish and other aquatic organisms. American Petroleum Institute Publication 4656, Washington, DC.

Jones-Lepp, T. L., D. A. Alvarez, J. D. Petty, and J. N. Huckins. 2004. Polar organic chemical integrative sampling and liquid chromatography-electrospray/ion-trap mass spectrometry for assessing selected prescription and illicit drugs in treated sewage effluents. Archives of Environmental Contamination and Toxicology 47:427-39.

Kallenborn, R., R. Gatermann, T. Nygard, J. Knutzen, and M. Schlabach. 2001. Synthetic musks in Norwegian marine fish samples collected in the vicinity of densely populated areas. Fresenius Environmental Bulletin 10:832-42.

Kolpin, D. W., E. T. Furlong, M. T. Meyer, E. M. Thurman, S. D. Zaugg, L. B. Barber, and H. T. Buxton. 2002. Pharmaceuticals, hormones, and other organic wastewater contaminants in US streams, 1999-2000: A national reconnaissance. Environmental Science and Technology 36:1202-11.

Lin, W. C., H. C. Chen, and W. H. Ding. 2005. Determination of pharmaceutical residues in waters by solidphase extraction and large-volume on-line derivatisation with gas chromatography-mass spectrometry. Journal of Chromatography 1065 A:279-85.

Lindsey, M.E., M. Meyer, and E. M. Thurman. 2001. Analysis of trace levels of sulfonamide and tetracycline antimicrobials in groundwater and surface water using solid-phase extraction and liquid chromatography/ mass spectrometry. Analytical Chemistry 73:4640-46.

Mahnik, S. N., B. Rizovski, M. Fuerhacker, and R. M. Mader. 2006. Development of an analytical method for the determination of anthracyclines in hospital effluents. Chemosphere 65:1419-25.

Miao, X. S., F. Bishay, M. Chen, and C. D. Metcalfe. 2004. Occurrence of antimicrobials in the final effluents of wastewater treatment plants in Canada. Environmental Science and Technology 38:3533-41. 
Mills, G. A., B. Vrana, I. Allan, D. A. Alvarez, J. N. Huckins, and R. Greenwood. 2007. Trends in monitoring pharmaceuticals and personal-care products in the aquatic environment by use of passive sampling devices. Analytical and Bioanalytical Chemistry 387:1153-57.

Nebot, C., S. W. Gibb, and K. G. Boyd. 2007. Quantification of human pharmaceuticals in water samples by high performance liquid chromatography-tandem mass spectrometry. Analytica Chimica Acta 598:87-94.

Paschke, A., J. Brummer, and G. Schuurmann. 2007. Silicone rod extraction of pharmaceuticals from water. Analytical and Bioanalytical Chemistry 387:1417-21.

Petrovic, M., M. Gros, and D. Barcelo. 2006. Multi-residue analysis of pharmaceuticals in wastewater by ultra-performance liquid chromatography-quadrupole-time-of-flight mass spectrometry. Journal of Chromatography $1124 \mathrm{~A}: 68-81$.

Petrovic, M., M. D. Hernando, M. S. Diaz-Cruz, and D. Barcelo. 2005. Liquid chromatography-tandem mass spectrometry for the analysis of pharmaceutical residues in environmental samples: A review. Journal of Chromatography $1067 \mathrm{~A}: 1-14$.

Petty, J. D., J. N. Huckins, D. A. Alvarez, W. G. Brumbaugh, W. L. Granor, R. W. Gale, A. C. Rastall, T. L. Jones-Lepp, T. J. Leiker, C. E. Rostad, and E. T. Furlong. 2004. A holistic passive integrative sampling approach for assessing the presence and potential impacts of waterborne environmental contaminants. Chemosphere 54:695-705.

Pozo, O. J., C. Guerrero, J. V. Sancho, M. Ibanez, E. Pitarch, E. Hogendoorn, and F. Hernandez. 2006. Efficient approach for the reliable quantification and confirmation of antibiotics in water using on-line solidphase extraction liquid chromatography/tandem mass spectrometry. Journal of Chromatography 11103A:83-93.

Quintana, J. B., J. Carpinteiro, I. Rodriguez, R. A. Lorenzo, A. M. Carro, and R. Cela. 2004. Determination of natural and synthetic estrogens in water by gas chromatography with mass spectrometric detection. Journal of Chromatography $1024 \mathrm{~A}: 177-85$.

Reddersen, K., and T. Heberer. 2003. Multi-compound methods for the detection of pharmaceutical residues in various waters applying solid phase extraction (SPE) and gas chromatography with mass spectrometric (GC-MS) detection. Journal of Separation Science 26:1443-50.

Roberts, P. H., and P. Bersuder. 2006. Analysis of OSPAR priority pharmaceuticals using high-performance liquid chromatography-electrospray ionisation tandem mass spectrometry. Journal of Chromatography 1134A: 143-50.

Roberts, P. H., and K. V. Thomas. 2006. The occurrence of selected pharmaceuticals in wastewater effluent and surface waters of the lower Tyne catchment. Science of the Total Environment 356:143-53.

Rodriguez-Mozaz, S., M. J. Lopez de Alda, and D. Barcelo. 2004. Picogram per liter level determination of estrogens in natural waters and waterworks by a fully automated on-line solid-phase extractionliquid chromatography-electrospray tandem mass spectrometry method. Analytical Chemistry 76:6998-7006.

Rodriguez-Mozaz, S., M. J. Lopez de Alda, and D. Barcelo. 2007. Advantages and limitations of on-line solid phase extraction coupled to liquid chromatography-mass spectrometry technologies versus biosensors for monitoring of emerging contaminants in water. Journal of Chromatography $1152 \mathrm{~A}: 97-115$.

Samuelsen, O. B., V. Torsvik, and A. Ervik. 1992. Long-rang changes in oxytetracycline concentration and bacterial resistance towards oxytetracycline in a fish farm sediment after medication. Science of the Total Environment 114:25-36.

Shareef, A., M. J. Angove, and J. D. Wells. 2006. Optimization of silylation using N-methyl-N-(trimethylsilyl)trifluoroacetamide,N,O-bis-(trimethylsilyl)-trifluoroacetamide and N-(tert-butyldimethylsilyl)-Nmethyltrifluoroacetamide for the determination of the estrogens estrone and 17 alpha-ethinylestradiol by gas chromatography-mass spectrometry. Journal of Chromatography $1108 \mathrm{~A}: 121-28$.

Stolker, A. A. M., W. Niesing, E. A. Hogendoorn, J. F. M. Versteegh, R. Fuchs, and U. A. T. Brinkman. 2004. Liquid chromatography with triple-quadrupole or quadrupole-time of flight mass spectrometry for screening and confirmation of residues of pharmaceuticals in water. Analytical and Bioanalytical Chemistry 378:955-63.

Ternes, T. A. 1998. Occurrence of drugs in German sewage treatment plants and rivers. Water Research 32:3245-60.

Ternes, T. A., M. Bonerz, N. Herrmann, D. Loffler, E. Keller, B. Bago Lacida, and A. C. Alder. 2005. Determination of pharmaceuticals, iodinated contrast media and musk fragrances in sludge by LC/ tandem MS and GC/MS. Journal of Chromatography $1067 \mathrm{~A}: 213-23$. 
Ternes, T. A., A. Joss, and H. Siegrist. 2004. Scrutinizing pharmaceuticals and personal care products in wastewater treatment. Environmental Science and Technology 38:392A-99A.

Togola, A., and H. Budzinski. 2007. Development of polar organic integrative samplers for analysis of pharmaceuticals in aquatic systems. Analytical Chemistry 79:6734-41.

Togola, A., and H. Budzinski. 2008. Multi-residue analysis of pharmaceutical compounds in aqueous samples. Journal of Chromatography 1177 A:150-58.

Thomas, K. V., and M. J. Hilton. 2004. The occurrence of selected human pharmaceutical compounds in UK estuaries. Marine Pollution Bulletin 49:436-44.

Trenholm, R. A., B. J. Vanderford, J. C. Holady, D. J. Rexing, and S. A. Snyder. 2006. Broad range analysis of endocrine disruptors and pharmaceuticals using gas chromatography and liquid chromatography tandem mass spectrometry. Chemosphere 65:1990-98.

Verenitch, S. S., C. J. Lowe, and A. Mazumder. 2006. Determination of acidic drugs and caffeine in municipal wastewaters and receiving waters by gas chromatography-ion trap tandem mass spectrometry. Journal of Chromatography 1116 A: 193-203.

Vrana, B., G. A. Mills, I. J. Allan, E. Dominiak, K. Svensson, J. Knutsson, G. Morrison, and R. Greenwood. 2005. Passive sampling techniques for monitoring pollutants in water. TrAC Rrends in Analytical Chemistry 24:845-68.

Vrana, B., G. A. Mills, E. Dominiak, and R. Greenwood. 2006. Calibration of the Chemcatcher passive sampler for the monitoring of priority organic pollutants in water. Environmental Pollution 142:333-43.

Weigel, S., R. Kallenborn, and H. Hühnerfuss. 2004. Simultaneous solid-phase extraction of acidic, neutral and basic pharmaceuticals from aqueous samples at ambient (neutral) $\mathrm{pH}$ and their determination by gas chromatography-mass spectrometry. Journal of Chromatography 1023 A:183-95.

Weigel, S., J. Kuhlmann, and H. Hühnerfuss. 2002. Drugs and personal care products as ubiquitous pollutants: Occurrence and distribution of clofibric acid, caffeine and DEET in the North Sea. Science of the Total Environment 295:121-41.

Zuhlke, S., U. Dunnbier, and T. Heberer. 2004. Detection and identification of phenazone-type drugs and their microbial metabolites in ground and drinking water applying solid-phase extraction and gas chromatography with mass spectrometric detection. Journal of Chromatography 1050 A:201-9.

Zhang, Z. L., A. Hibberd, and J. L. Zhou. 2008. Analysis of emerging contaminants in sewage effluent and river water: Comparison from spot and passive sampling. Analytica Chimica Acta 607:37-44.

Zhang, Z. L., and J. L. Zhou. 2007. Simultaneous determination of various pharmaceuticals in envirenmental waters by solid-phase extraction-liquid chromatography-tandem mass spectrometry. Journal of Chromatography 1154 A:205-13.

Zhou, J. L., T. W. Fileman, S. Evans, P. Donkin, R. F. C. Mantoura, and S. J. Rowland. 1996. Seasonal distribution of dissolved pesticides and polynuclear aromatic hydrocarbons in the Humber estuary and Humber coastal zone. Marine Pollution Bulletin 32:599-608. 
